\title{
QuadraPure-Supported Palladium Nanocatalysts for Microwave-Promoted Suzuki Cross-Coupling Reaction under Aerobic Condition
}

\author{
Kin Hong Liew, ${ }^{1}$ Poh Lee Loh, ${ }^{1}$ Joon Ching Juan, ${ }^{2}$ \\ Mohd Ambar Yarmo, ${ }^{1}$ and Rahimi M. Yusop ${ }^{1}$ \\ ${ }^{1}$ School of Chemical Sciences and Food Technology, Faculty of Science and Technology, Universiti Kebangsaan Malaysia (UKM), \\ 43600 Bangi, Selangor Darul Ehsan, Malaysia \\ ${ }^{2}$ Nanotechnology \& Catalysis Research Centre (NANOCAT), University of Malaya, 50603 Kuala Lumpur, Malaysia
}

Correspondence should be addressed to Rahimi M. Yusop; rahimi@ukm.edu.my

Received 25 January 2014; Revised 8 June 2014; Accepted 8 June 2014; Published 25 June 2014

Academic Editor: Fabio B. Passos

Copyright (C) 2014 Kin Hong Liew et al. This is an open access article distributed under the Creative Commons Attribution License, which permits unrestricted use, distribution, and reproduction in any medium, provided the original work is properly cited.

Cross-linked resin-captured palladium (XL-QPPd) was readily prepared by simple physical adsorption onto the high loading QuadraPure macroporous resin and a subsequent reduction process. To enhance the mechanical stability, entrapped palladium nanocatalysts were cross-linked with succinyl chloride. Both transmission electron microscopy images and X-ray diffraction analysis revealed that the palladium nanoparticles were well dispersed with diameters ranging in $4-10 \mathrm{~nm}$. The catalyst performed good catalytic activity in microwave-promoted Suzuki cross-coupling reactions in water under aerobic condition with mild condition by using various aryl halides and phenylboronic acid. In addition, the catalyst showed an excellent recyclability without significant loss of catalytic activity.

\section{Introduction}

Over the past several decades, palladium is one of the most useful transition metal catalysts in variety of transformations in organic synthesis such as Mizoroki-Heck, Sonogashira coupling, Negishi coupling, Stille, and Suzuki coupling reaction [1-5]. The palladium-catalyzed Suzuki coupling reaction between aryl halides and organoboronic acid is an excellent method for the synthesis of various biaryl compounds, which constitute a wide range of fine chemicals, pharmaceuticals, and advanced materials [6-10]. Despite the great efficiency of homogeneous palladium catalysts in various organic reactions, they have several drawbacks to be resolved. The problems of homogeneous catalysts in recovering and recycling lead to the loss of metal and ligands and incorporation of impurities in the products [11]. For chemical and pharmaceutical industries, this is a task of great economic and environmental issues especially when expensive and/or toxic heavy metal complexes are employed [12]. To overcome these drawbacks, the use of ligand-free heterogeneous palladium catalysts is often desirable because it can be recovered and reused by simple filtration without any loss of catalytic activity [13].

Recently, many recoverable supported palladium catalysts have been reported to catalyze Suzuki coupling reactions in the absence of ligands such as polymers, biomaterials, porous silica, carbon nanotube, polyurea, and natural phosphate [13-19]. However, some supported catalysts allow to be reused as they are heterogeneous catalysts, but often result in significant loss of catalytic activities and the leaching of transition metal during the reaction [20]. The disposal of organic solvent after the Suzuki reaction is also a major environmental problem for pharmaceutical industries. The attention of using water as reaction medium for coupling reactions catalyzed by heterogeneous palladium catalyst was increasing due to the rising concerns for the environment [21]. Water is suitable for Suzuki coupling reaction since it is cheap, nontoxic, and of easy recovery of the products [13].

QuadraPure is attracting considerable attention as an alternative solid support for heterogeneous catalysis as well 
as for the formation of cross-linked captured palladium catalysts. QuadraPure is a commercial available polystyrene resin, which is widely used as a metal scavenger in variety of organometallic synthesis [22, 23]. This macroporous polystyrene QuadraPure is highly robust and chemically resistant-free flowing and it is compatible with organic, aqueous, protic, and aprotic media. Since QuadraPure is a metal scavenger, it is suitable to be used as a solid support for catalyst to avoid metal leaching problem. In this study, we have prepared a new cross-linked captured palladium (XL-QPPd) catalyst by incorporated $\mathrm{Pd}(\mathrm{OAc})_{2}$ in QuadraPure. The new catalyst showed good catalytic activity for microwave-promoted Suzuki coupling reaction to synthesis biaryls using water as a solvent. The microwave heating was applied in the heterogeneous system that can lead to higher reaction rate.

\section{Experimental Section}

2.1. Reagents and Materials. The solid support QuadraPure EDA (1.5-2.0 mmol/g loading) and high purity palladium acetate $\left(\mathrm{Pd}(\mathrm{OAc})_{2}, 99.99 \%\right)$ were obtained from SigmaAldrich Co., Inc. Bromobenzene (99\%), 4-bromoanisole ( $\geq 99 \%$ ), 1-bromo-4-nitrobenzene (99\%), 4-bromobenzotrifluoride (99\%), 4-iodoanisole (98\%), 4-chloroanisole (99\%), chlorobenzene (99.99\%), iodobenzene (98\%), phenylboronic acid (95\%), succinyl chloride (95\%), and $\mathrm{K}_{2} \mathrm{CO}_{3}(\geq 99 \%)$ were used in their commercially available form. Triethylamine was dried with magnesium sulfate before use. $10 \%$ Hydrazine hydrate (80\%) solution was prepared by dissolve it in methanol solvent. Other analytical solvents were used as received.

\subsection{Preparation of Captured Palladium Particles onto Quadra-} Pure Particles (XL-QPPd). The cross-linked captured palladium (XL-QPPd) was readily prepared by treating a mixture of solid support QuadraPure with palladium acetate in toluene at $80^{\circ} \mathrm{C}$ for $10 \mathrm{~min}$ and then at room temperature for 2 hours to yield brown colored resin-captured. The resulting resin was cross-linked with succinyl chloride and triethylamine in dry DMF solvent. Subsequently, the resin was filtered and then treated with hydrazine hydrate in methanol $(10 \%)$ at room temperature to give black resin palladium catalyst $(1.5 \mathrm{mmol}$ of $\mathrm{Pd} / \mathrm{g})$. The color of the resin changed to black because of the trapped palladium nanoparticles, $\mathrm{Pd}^{0}$ $[24,25]$.

2.3. General Procedure for Suzuki Coupling Reaction of Aryl Halides Using XL-QPPd as Catalyst. Phenylboronic acid (91 mg, $0.75 \mathrm{mmol}, 1.5$ equiv.), aryl halides $(0.5 \mathrm{mmol}$ ), potassium carbonate $(101 \mathrm{mg}, 0.75 \mathrm{mmol}, 1.5$ equiv.), water $(2 \mathrm{~mL})$, and XL-QPPd resin (16.7 mg, $0.05 \mathrm{mmol}$, and $5 \mathrm{~mol} \%$ of aryl halide) were added into a $10 \mathrm{~mL}$ vial and heated in a microwave $\left(120^{\circ} \mathrm{C}, 100 \mathrm{w}\right)$ with magnetic stirring for $10 \mathrm{~min}$. The XL-QPPd resin was recovered by simple filtration with solid phase extraction (SPE) and washed with acetone and dried at room temperature. The reaction mixture was extracted with ethyl acetate $(3 \times 10 \mathrm{~mL})$. The organic layers were combined and washed with distilled water, dried over $\mathrm{MgSO}_{4}$, filtered, and concentrated under reduced pressure. The crude product was further purified by column chromatography on silica gel to yield the final product and characterized by NMR.

2.4. Instrumentation. The field emission scanning electron microscope (FESEM) measurements were conducted by using a SUPRA 55VP (CARL ZEISS., Oberkochen, Germany) electron microscopy. The existence of palladium on the surface of XL-QPPd resin was carried out with an energydispersive X-ray (EDX) analysis (equipped with the SEM). TEM measurements were performed under vacuum by a CM-12 (PHILIPS) transmission electron microscopy. The XL-QPPd resin was dispersed on acetone solution under ultrasonic vibration for 10 mins and one drop of the suspension evaporated onto a carbon-coated copper grid for TEM measurement. The X-ray powder diffraction (XRD) pattern of the catalyst was taken using a D8-Advance (BRUKER, Germany) X-ray diffractometer system. Diffraction data were recorded using continuous scanning at $8 \mathrm{deg} / \mathrm{min}$, step 0.025. ${ }^{1} \mathrm{H}$ and ${ }^{13} \mathrm{C}$ NMR data of products were obtained using a JEOL ECP $400 \mathrm{MHz}$ (Superconductor) and BRUKER AVANCE $111600 \mathrm{MHz}$ spectrometer with $\mathrm{CDCl}_{3}$ as the solvent. The amount of Pd was determined by ICP-MS (Optima 2000 DV).

\section{Results and Discussion}

3.1. Synthesis and Characterization of Cross-Linked Captured Palladium. The cross-linked captured palladium resin (XLQPPd) was readily prepared via a 3 -step procedure $[25,26]$. This was based on physical entrapment by the polymers and also on electronic interactions between the electrons of the aryl rings of polystyrene-based polymers and vacant orbitals onto the catalysts, resulting in stronger connections between the components [27, 28]. Firstly, palladium acetate was immobilized and embedded on the surface of QuadraPure in toluene under the atmosphere condition. Second, the catalyst was cross-linked with succinyl chloride to enhance the chemical and physical stability of the catalyst which mean that the palladium is not easy to leach out from the resin. Lastly, the addition of hydrazine hydrate in methanol act as a reducing agent to reduce $\mathrm{Pd}^{2+}$ to $\mathrm{Pd}^{0}$.

The XRD patterns of the naked QuadraPure and the XL-QPPd resin are shown in Figure 1. The result shows the presence of palladium nanoparticles on the QuadraPure surface. After the reduction step, the reflection peaks are observed in XRD pattern at $2 \theta=40.1^{\circ}, 46.6^{\circ}$, and $68.3^{\circ}$ corresponds to the (111), (200), and (220) planes of fcc (facecentered cubic) lattice, respectively. This data matched the data of $\mathrm{Pd}^{0}$ provided by the ASTM (American Society for Testing and Materials) and previous work performed by Shen et al. [29]. The average nanoparticle size is calculated to be $8 \mathrm{~nm}$ by using Scherrer formula.

The size and morphology of the supports are revealed by SEM. Figure 2 shows the SEM images of (a) and (b) naked 
TABLE 1: Microwave-promoted Suzuki coupling of aryl halides with phenylboronic acid catalyzed by XL-QPPd nanoparticles.

\begin{tabular}{|c|c|c|c|}
\hline Entry & $\mathrm{R}_{1}$ & $\mathrm{X}$ & Yield $^{\mathrm{b}} \%$ \\
\hline 1 & $\mathrm{H}$ & $\mathrm{Br}$ & 85 \\
\hline 2 & $\mathrm{OMe}$ & $\mathrm{Br}$ & 90 \\
\hline 3 & $\mathrm{NO}_{2}$ & $\mathrm{Br}$ & 97 \\
\hline 4 & $\mathrm{CF}_{3}$ & $\mathrm{Br}$ & 82 \\
\hline 5 & $\mathrm{Me}$ & $\mathrm{Br}$ & 85 \\
\hline 6 & $\mathrm{COCH}_{3}$ & $\mathrm{Br}$ & 97 \\
\hline 7 & $\mathrm{H}$ & I & 87 \\
\hline 8 & $\mathrm{OMe}$ & I & 96 \\
\hline 9 & $\mathrm{H}$ & $\mathrm{Cl}$ & 18 \\
\hline 10 & $\mathrm{OMe}$ & $\mathrm{Cl}$ & 23 \\
\hline
\end{tabular}

${ }^{a}$ Reaction condition: phenylboronic acid $(0.75 \mathrm{mmol})$, aryl halide $(0.5 \mathrm{mmol}), \mathrm{K}_{2} \mathrm{CO}_{3}(0.75 \mathrm{mmol}), \mathrm{XL}-\mathrm{QPPd}(0.05 \mathrm{mmol})$, water $(2 \mathrm{~mL})$, and microwave, $120^{\circ} \mathrm{C}$.

${ }^{\mathrm{b}}$ Based on the isolated yield of the monosubstituted product after column chromatography on silica gel.

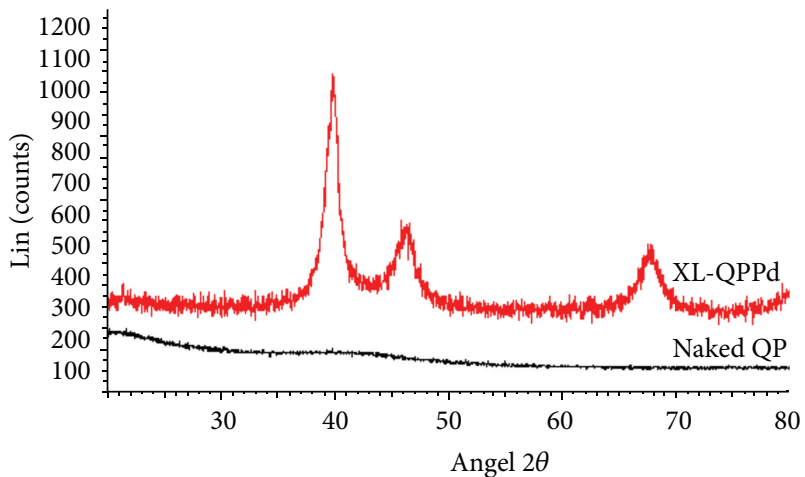

FIGURE 1: XRD patterns of the naked QuadraPure and the XL-QPPd resin.

QuadraPure, (c) original XL-QPPd resin, and (d) XL-QPPd after ten runs. As shown in Figures 2(c) and 2(d), the particles have been formed on the surface of QuadraPure in the entire observed surface, while, for the resin, the clusters are observed. The morphology of XL-QPPd resin after ten runs does not show obvious difference except that the agglomerates become more compact. Scanning electron microscopy with energy dispersive X-ray spectroscopy (SEM-EDX) is the best known and most widely used to determine the elemental composition of a sample. The SEM-EDX analysis of XL-QPPd resin confirmed the immobilization of palladium onto the surface of resin without any impurity (Figure 3).

The size and distribution of the $\mathrm{Pd}^{0}$ nanoparticles on QuadraPure are analyzed using TEM (CM-12). The TEM micrograph and size distribution show that the $\mathrm{Pd}^{0}$ nanoparticles are well-dispersed onto the resin with an average size of
$7.4 \pm 3 \mathrm{~nm}$ in diameter (Figure 4). It is obviously shown that the nanoparticles are spherical in shape.

3.2. Suzuki Cross-Coupling Reactions. To investigate the catalytic activity of the XL-QPPd resin, Suzuki cross-coupling reactions are carried out in the presence of resin $(5 \mathrm{~mol} \%$ based on Pd content) in water for 10 mins under microwave condition $\left(120^{\circ} \mathrm{C}, 100 \mathrm{w}\right)$ under air condition (Table 1). The results shows that XL-QPPd resins are good catalysts for the Suzuki cross-coupling reaction by giving good yield with high purity for the aryl bromides and aryl iodides (Table 1, entry 1-8). However, the resins give poor yield with aryl chlorides under the same reaction condition (Table 1, Entries 9 and 10). Aryl chlorides are unreactive towards Suzuki crosscoupling reaction (relative reactivity: $\mathrm{I}>\mathrm{OTf}>\mathrm{Br} \ggg \mathrm{Cl}$ ) due to the strength of the Ar-Cl bond ( $\mathrm{Ph}-\mathrm{X}: \mathrm{Cl}$ (96) $\mathrm{Br}(81)>\mathrm{I}$ $(65 \mathrm{kcal} / \mathrm{mol}))$ [30]. It hinders the formation of $\mathrm{Ar}-\mathrm{Cl}$ bond between the organoboronic acid with aryl halides. After the completion of the reaction, the resin can be recovered by simple filtration and washed with solvents to remove all the impurities. Therefore, the XL-QPPd resins are good heterogeneous catalysts for Suzuki cross-coupling reaction (aryl bromide and aryl iodide).

A filtration test was carried out to investigate the amounts of active Pd species leach out into the solution during the reaction. Each supported Pd catalyst was placed under the Suzuki reaction condition (microwave, $120^{\circ} \mathrm{C}$ for $12 \mathrm{~min}$ ) and supernatant collected. The filtrate was then used for a Suzuki cross-coupling reaction between 4-bromoacetophenone and boronic acid. The filtrate from XL-QPPd afforded conversions of $3 \%$, indicating that minimal amount of palladium leached out from XL-QPPd. 


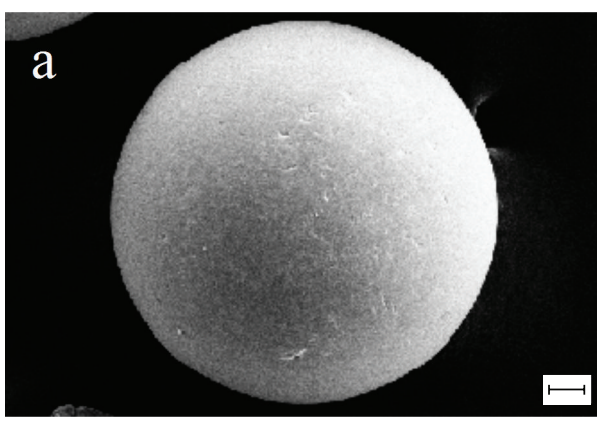

(a)

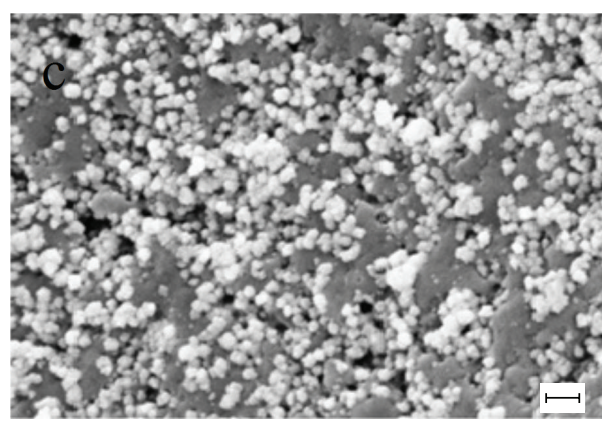

(c)

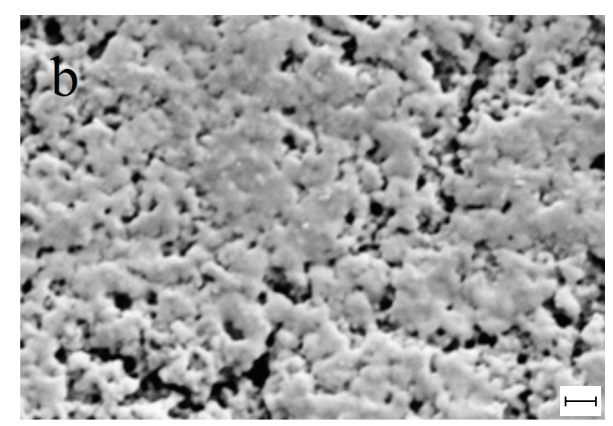

(b)

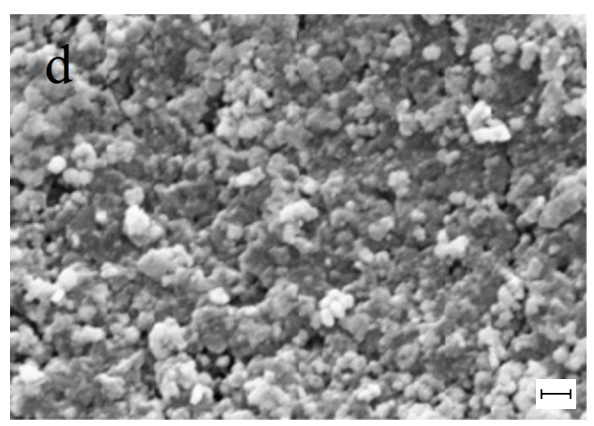

(d)

FIGURE 2: SEM images of (a) and (b) naked QuadraPure (scale bar $20 \mu \mathrm{m}$ ), (c) original XL-QPPd resin and (d) XL-QPPd after ten runs (scale bar: $200 \mathrm{~nm}$ ).

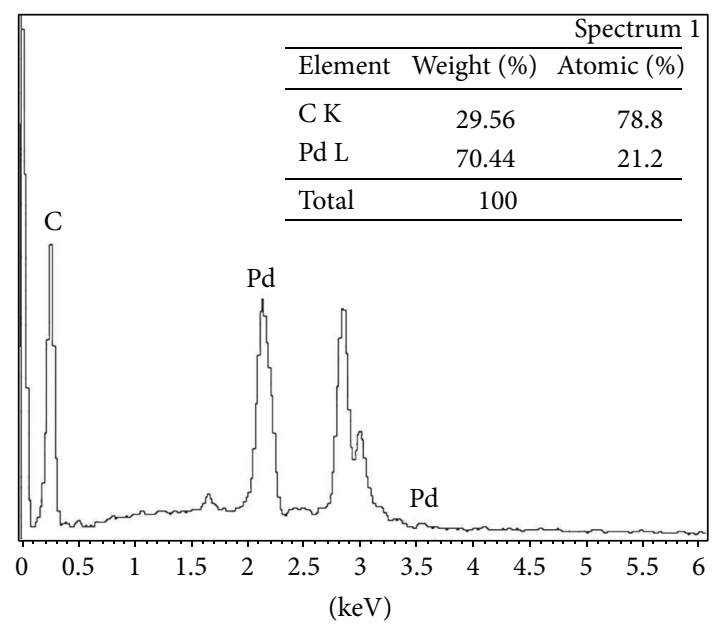

Full scale 3612 cts cursor: 0.008 (2851 cts)

FIGURE 3: EDX analysis of XL-QPPd resin.

In order to investigate the recyclability of the XLQPPd resins, the Suzuki cross-coupling reaction between the phenylboronic acid and 4-bromoacetophenone is examined (Figure 5). The catalysts are performed consistent catalytic activity after 10 runs. The results show that XL-QPPd resins can be reused for at least 10 times with no significant loss of catalytic activity, with simple filtration and washing. The leaching of $\mathrm{Pd}^{0}$ into the reaction mixture from the recovered XL-QPPd resins supported is analyzed using ICP-MS. The minimal amount of palladium leached out from XL-QPPd resins is only $0.21 \mathrm{ppm}$, which indicates that only small amount of catalysts leached out into the reaction mixture.

A comparison of the present method with others reported in the literature using nanoparticles and microwave heating was done and the results are summarized in Table 2. Palladium complex with salicylaldehyde N(4)-hexamethyleneiminylthiosemicarbazone was used as catalyst in Suzuki coupling reaction, but it took longer time to complete the reaction [31]. Chitosan-supported catalyst reported by Yi et al. showed higher yield in the presence of phase transfer agent TBAB in the reaction mixture [32]. In case of Tentagel and Macronet MN100 HPS (entries 3 and 4) needs extra cross-linking steps to reduce metal leaching problem $[25,33]$. This better result can be attributed to a better solubilization of the base in a solvent with higher polarity. de Luna Martins et al. and Arvela and leadbeater have used $\mathrm{Pd} / \mathrm{C}$ and $\mathrm{Pd}_{2} \mathrm{dba}_{3}$ for microwave-prompted Suzuki coupling reaction in toluene and $\mathrm{DMF} / \mathrm{H}_{2} \mathrm{O}$ as solvent, but no recycling was reported $[34,35]$. Qi and coworkers have reported that only $0.2 \mathrm{~mol} \%$ loading of $\mathrm{Pd}\left(\gamma-\mathrm{Al}_{2} \mathrm{O}_{3}-\mathrm{Pd}\right)$ was needed to obtain crosscoupling products in the presence of $\mathrm{DMF} / \mathrm{H}_{2} \mathrm{O}$. In the present work, a relatively high Pd loading was used, but it only needs a low amount of catalyst for the Suzuki reaction due to the high loading of QuadraPure resin.

\section{Conclusions}

In conclusion, we have successfully prepared the cross-linked captured palladium resin (XL-QPPd) as a heterogeneous 
TABLE 2: Comparison with other catalyst systems.

\begin{tabular}{|c|c|c|c|c|}
\hline Entry & Catalyst support & $\mathrm{Pd}(\mathrm{mol} \%)$ & Phase transfer agent/solvent & Reference \\
\hline 1 & Pd complex & $1 \mathrm{mM}$ & $\mathrm{DMF} / \mathrm{H}_{2} \mathrm{O}$ & {$[31]$} \\
\hline 2 & Chitosan & 0.5 & TBAB/dioxane & {$[32]$} \\
\hline 3 & Aminomethylated TentaGel & 10.0 & $\mathrm{H}_{2} \mathrm{O}$ & {$[25]$} \\
\hline 4 & Macronet MN100 HPS & 2.0 & $\mathrm{H}_{2} \mathrm{O}$ & {$[33]$} \\
\hline 5 & $\mathrm{Pd}_{2} \mathrm{dba}_{3}$ & 1.0 & Toluene & {$[34]$} \\
\hline 6 & $\mathrm{Pd} / \mathrm{C}$ & 1.0 & $\mathrm{DMF} / \mathrm{H}_{2} \mathrm{O}$ & [35] \\
\hline 7 & $\gamma-\mathrm{Al}_{2} \mathrm{O}_{3}-\mathrm{Pd}$ & 0.2 & $\mathrm{DMF} / \mathrm{H}_{2} \mathrm{O}$ & {$[36]$} \\
\hline 8 & XL-QPPd & 10.0 & $\mathrm{H}_{2} \mathrm{O}$ & Present \\
\hline
\end{tabular}

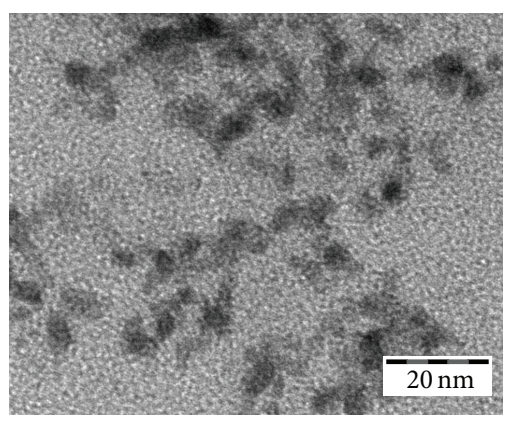

(a)

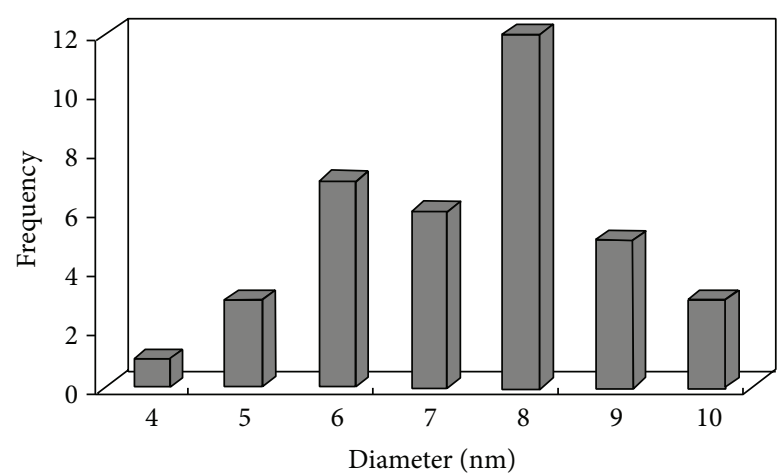

(b)

FIGURE 4: Transmission electron microscopy (TEM) observed physically captured and entrapped on the QuadraPure resin (a) and size distribution of $\mathrm{Pd}^{0}$ nanoparticles (b).

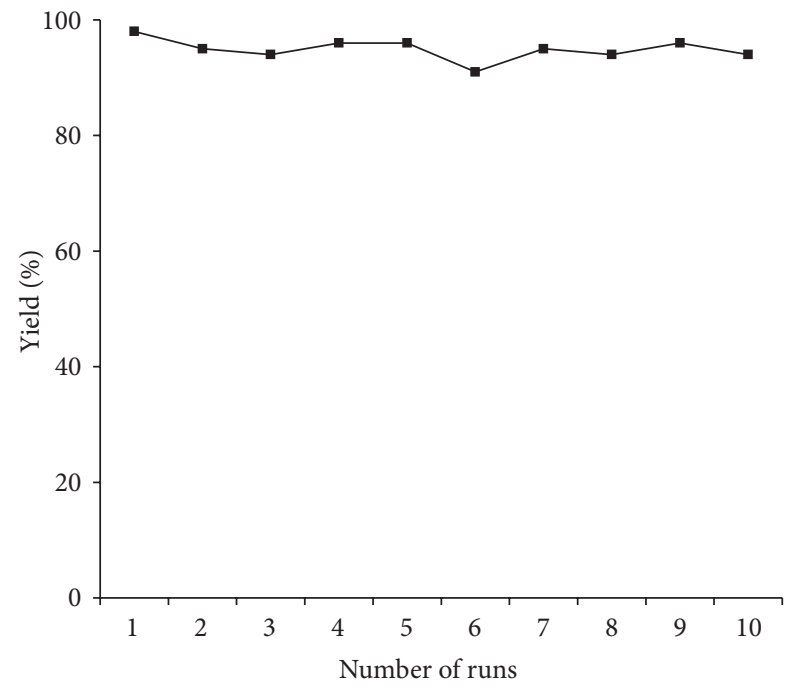

FIGURE 5: Recyclability of XL-QPPd resins on Suzuki cross-coupling reaction between the phenylboronic acid and 4-bromoacetophenone.

catalyst via a simple method. The XL-QPPd exhibited a good catalytic activity for microwave-promoted Suzuki crosscoupling reactions under aerobic condition with low leaching of palladium from the resin. Moreover, the catalyst can be recovered and reused for several times without any loss of catalytic activity by simple filtration.

\section{Conflict of Interests}

The authors declare that there is no conflict of interests regarding the publication of this paper.

\section{Acknowledgments}

The authors are thankful to Universiti Kebangsaan Malaysia for financial support for research Grants AP/2012/017, FRGS/ 1/2012/ST01/UKM/02/1, and DLP/2013/002 and to the supporting staffs of School of Chemical Sciences \& Food Technology that has contributed greatly to our research.

\section{References}

[1] A. Kumar, G. K. Rao, and A. K. Singh, "Organochalcogen ligands and their palladium(II) complexes: synthesis to catalytic activity for Heck coupling," RSC Advances, vol. 2, no. 33, pp. 12552-12574, 2012.

[2] M. Bakherad, "Recent progress and current applications of Sonogashira coupling reaction in water," Applied Organometallic Chemistry, vol. 27, no. 3, pp. 125-140, 2013.

[3] M. M. Heravi, E. Hashemi, and N. Nazari, "Negishi coupling: an easy progress for $\mathrm{C}-\mathrm{C}$ bond construction in total synthesis," Molecular Diversity, vol. 18, pp. 441-472, 2014. 
[4] M. M. Heravi, E. Hashemi, and F. Azimian, "Recent developments of the Stille reaction as a revolutionized method in total synthesis," Tetrahedron, vol. 70, no. 1, pp. 7-21, 2014.

[5] R. Martin and S. L. Buchwald, "Palladium-catalyzed suzukimiyaura cross-coupling reactions employing dialkylbiaryl phosphine ligands," Accounts of Chemical Research, vol. 41, no. 11, pp. 1461-1473, 2008.

[6] K. Okumura, T. Tomiyama, S. Okuda, H. Yoshida, and M. Niwa, "Origin of the excellent catalytic activity of Pd loaded on ultra-stable y zeolites in Suzuki-Miyaura reactions," Journal of Catalysis, vol. 273, no. 2, pp. 156-166, 2010.

[7] C. Torborg and M. Beller, "Recent applications of palladiumcatalyzed coupling reactions in the pharmaceutical, agrochemical, and fine chemical industries," Advanced Synthesis and Catalysis, vol. 351, no. 18, pp. 3027-3043, 2009.

[8] T. Brenstrum, J. Clattenburg, J. Britten et al., "Phosphorinanes as ligands for palladium-catalyzed cross-coupling chemistry," Organic Letters, vol. 8, no. 1, pp. 103-105, 2006.

[9] R. M. Yusop, A. Unciti-Broceta, and M. Bradley, "A highly sensitive fluorescent viscosity sensor," Bioorganic and Medicinal Chemistry Letters, vol. 22, no. 18, pp. 5780-5783, 2012.

[10] A. Unciti-Broceta, R. M. Yusop, P. R. Richardson, J. G. A. Walton, and M. Bradley, "A fluorescein-derived anthocyanidininspired pH sensor," Tetrahedron Letters, vol. 50, no. 26, pp. 3713-3715, 2009.

[11] K. Karami, M. Ghasemi, and N. H. Naeini, "Palladium nanoparticles supported on polymer: an efficient and reusable heterogeneous catalyst for the Suzuki cross-coupling reactions and aerobic oxidation of alcohols," Catalysis Communications, vol. 38, pp. 10-15, 2013.

[12] D. J. Cole-Hamilton, "Homogeneous catalysis-new approaches to catalyst separation, recovery, and recycling," Science, vol. 299, no. 5613, pp. 1702-1706, 2003.

[13] M. M. Dell'Anna, M. Mali, P. Mastrorilli, A. Rizzuti, C. Ponzoni, and C. Leonelli, "Suzuki-Miyaura coupling under air in water promoted by polymer supported palladium nanoparticles," Journal of Molecular Catalysis A: Chemical, vol. 366, pp. 186194, 2013.

[14] K. Bester, A. Bukowska, and W. Bukowski, "Synthesis of gel-type imino-amino functionalized methacrylate-styrene terpolymers as supports for palladium catalysts for the Suzuki-Miyaura reaction," Applied Catalysis A: General, vol. 443-444, pp. 181190, 2012.

[15] S. E. S. Leonhardt, A. Stolle, B. Ondruschka et al., "Chitosan as a support for heterogeneous Pd catalysts in liquid phase catalysis," Applied Catalysis A, vol. 379, no. 1-2, pp. 30-37, 2010.

[16] V. Polshettiwar, C. Len, and A. Fihri, "Silica-supported palladium: sustainable catalysts for cross-coupling reactions," Coordination Chemistry Reviews, vol. 253, no. 21-22, pp. 2599-2626, 2009.

[17] Y. S. Chun, J. Y. Shin, C. E. Song, and S. G. Lee, "Palladium nanoparticles supported onto ionic carbon nanotubes as robust recyclable catalysts in an ionic liquid," Chemical Communications, no. 8, pp. 942-944, 2008.

[18] C. Ramarao, S. V. Ley, S. C. Smith, I. M. Shirley, and N. DeAlmeida, "Encapsulation of palladium in polyurea microcapsules," Chemical Communications, no. 10, pp. 1132-1133, 2002.

[19] A. Hassine, S. Sebti, A. Solhy et al., "Palladium supported on natural phosphate: catalyst for Suzuki coupling reactions in water," Applied Catalysis A: General, vol. 450, pp. 13-18, 2013.
[20] M. Sudip, R. Gadi, J. Ashutosh, B. Mubeen, and S. Yoel, "Heterogeneous palladium-catalysed Heck reaction of aryl chlorides and styrene in water under mild conditions," Advanced Synthesis \& Catalysis, vol. 344, pp. 348-354, 2002.

[21] Y. Uozumi and Y. Nakai, "An amphiphilic resin-supported palladium catalyst for high-throughput cross-coupling in water," Organic Letters, vol. 4, no. 17, pp. 2997-3000, 2002.

[22] C. D. Smith, I. R. Baxendale, S. Lanners, J. J. Hayward, S. C. Smith, and S. V. Ley, "[3 + 2] Cycloaddition of acetylenes with azides to give 1,4-disubstituted 1,2,3-triazoles in a modular flow reactor," Organic and Biomolecular Chemistry, vol. 5, no. 10, pp. 1559-1561, 2007.

[23] T. Noël and S. L. Buchwald, "Cross-coupling in flow," Chemical Society Reviews, vol. 40, no. 10, pp. 5010-5029, 2011.

[24] R. M. Yusop, A. Unciti-Broceta, E. M. V. Johansson, R. M. Sánchez-Martín, and M. Bradley, "Palladium-mediated intracellular chemistry," Nature Chemistry, vol. 3, no. 3, pp. 239-243, 2011.

[25] J. K. Cho, R. Najman, T. W. Dean, O. Ichihara, C. Muller, and M. Bradley, "Captured and cross-linked palladium nanoparticles," Journal of the American Chemical Society, vol. 128, no. 19, pp. 6276-6277, 2006.

[26] R. Najman, J. K. Cho, A. F. Coffey, J. W. Davies, and M. Bradley, "Entangled palladium nanoparticles in resin plugs," Chemical Communications, no. 47, pp. 5031-5033, 2007.

[27] S. Kobayashi and S. Nagayama, "A microencapsulated Lewis acid. A new type of polymer-supported Lewis acid catalyst of wide utility in organic synthesis," Journal of the American Chemical Society, vol. 120, no. 12, pp. 2985-2986, 1998.

[28] S. Kobayashi, M. Endo, and S. Nagayama, "Catalytic asymmetric dihydroxylation of olefins using a recoverable and reusable polymer-supported osmium catalyst," Journal of the American Chemical Society, vol. 121, no. 48, pp. 11229-11230, 1999.

[29] C. M. Shen, Y. K. Su, H. T. Yang, T. Z. Yang, and H. J. Gao, "Synthesis and characterization of $n$-octadecayl mercaptanprotected palladium nanoparticles," Chemical Physics Letters, vol. 373, no. 1-2, pp. 39-45, 2003.

[30] X.-F. Wu, P. Anbarasan, H. Neumann, and M. Beller, "From noble metal to Nobel Prize: palladium-catalyzed coupling reactions as key methods in organic synthesis," Angewandte Chemie-International Edition, vol. 49, no. 48, pp. 9047-9050, 2010.

[31] I. D. Kostas, G. A. Heropoulos, D. Kovala-Demertzi et al., "Microwave-promoted Suzuki-Miyaura cross-coupling of aryl halides with phenylboronic acid under aerobic conditions catalyzed by a new palladium complex with a thiosemicarbazone ligand," Tetrahedron Letters, vol. 47, no. 26, pp. 4403-4407, 2006.

[32] S. Yi, D. Lee, E. Sin, and Y. Lee, "Chitosan-supported palladium $(0)$ catalyst for microwave-prompted Suzuki crosscoupling reaction in water," Tetrahedron Letters, vol. 48, no. 38, pp. 6771-6775, 2007.

[33] H. Miyamura, R. Matsubara, Y. Miyazaki, and S. Kobayashi, "Aerobic oxidation of alcohols at room temperature and atmospheric conditions catalyzed by reusable gold nanoclusters stabilized by the benzene rings of polystyrene derivatives," Angewandte Chemie -International Edition, vol. 46, no. 22, pp. 4151-4154, 2007.

[34] D. de Luna Martins, L. C. S. Aguiar, and O. A. C. Antunes, "Microwave promoted Suzuki reactions between aroyl chlorides and boronic acids catalyzed by heterogeneous and homogeneous phosphine-free palladium catalysts," Journal of 
Organometallic Chemistry, vol. 696, no. 15-16, pp. 2845-2849, 2011.

[35] R. K. Arvela and N. E. Leadbeater, "Suzuki coupling of aryl chlorides with phenylboronic acid in water, using microwave heating with simultaneous cooling," Organic Letters, vol. 7, no. 11, pp. 2101-2104, 2005.

[36] G. F. Feng, F. J. Liu, C. Lin, W. T. Li, S. N. Wang, and C. Z. Qi, "Crystalline mesoporous $\gamma-\mathrm{Al}_{2} \mathrm{O}_{3}$ supported palladium: novel and efficient catalyst for Suzuki-Miyaura reaction under controlled microwave heating," Catalysis Communications, vol. 37, pp. 27-31, 2013. 

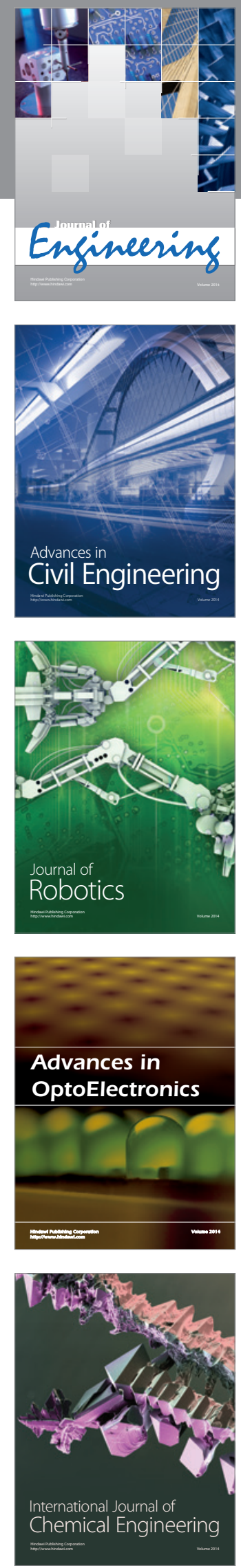

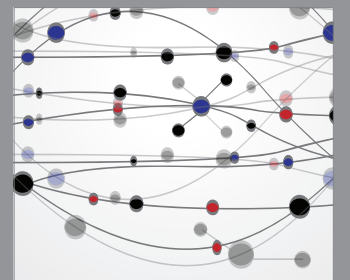

The Scientific World Journal
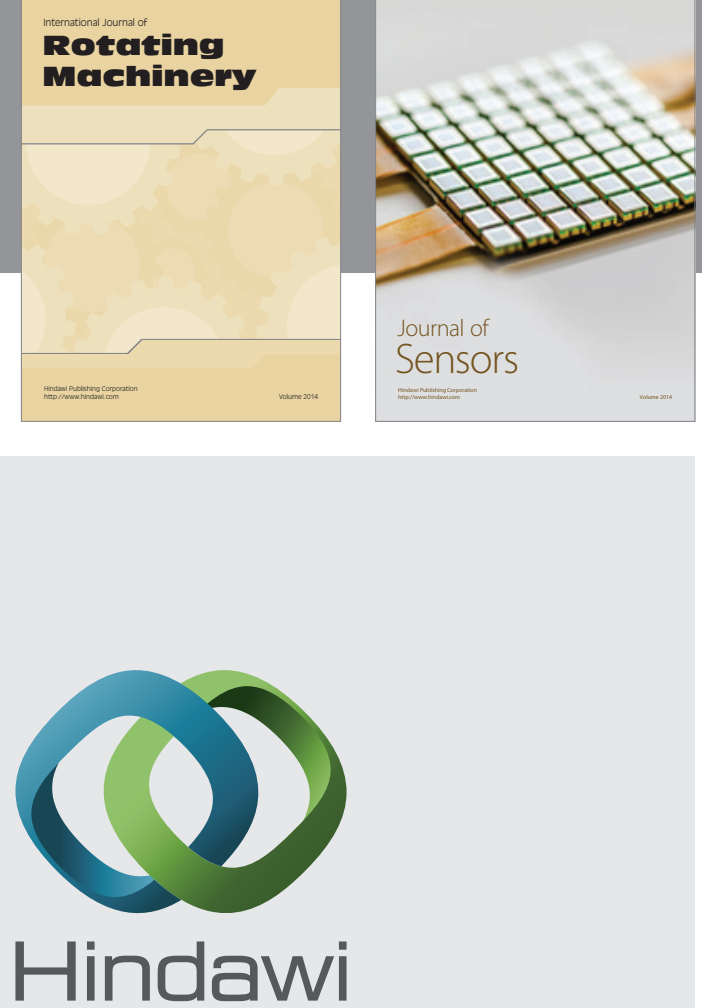

Submit your manuscripts at http://www.hindawi.com
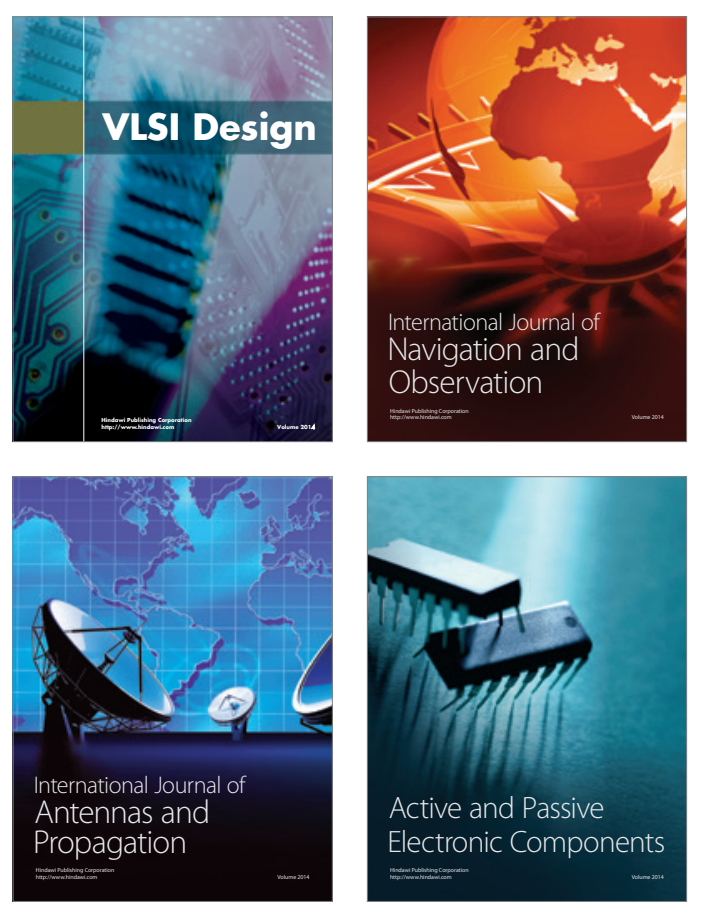
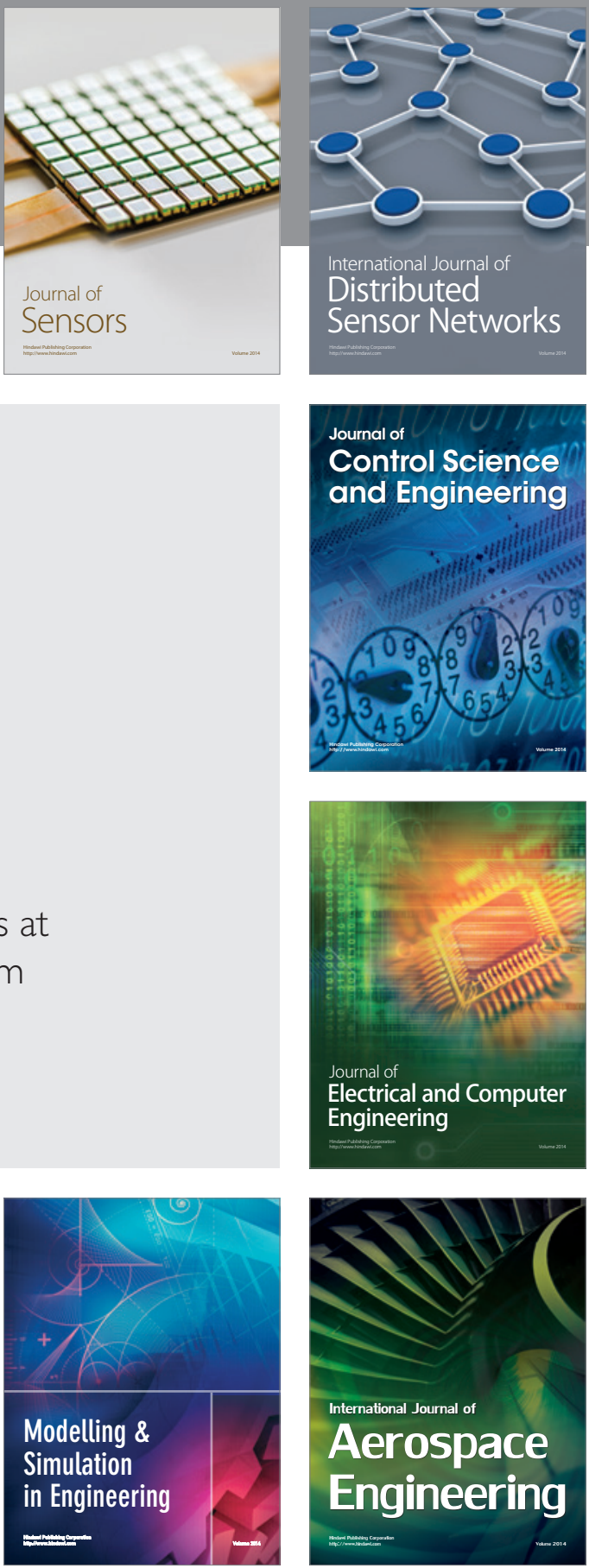

Journal of

Control Science

and Engineering
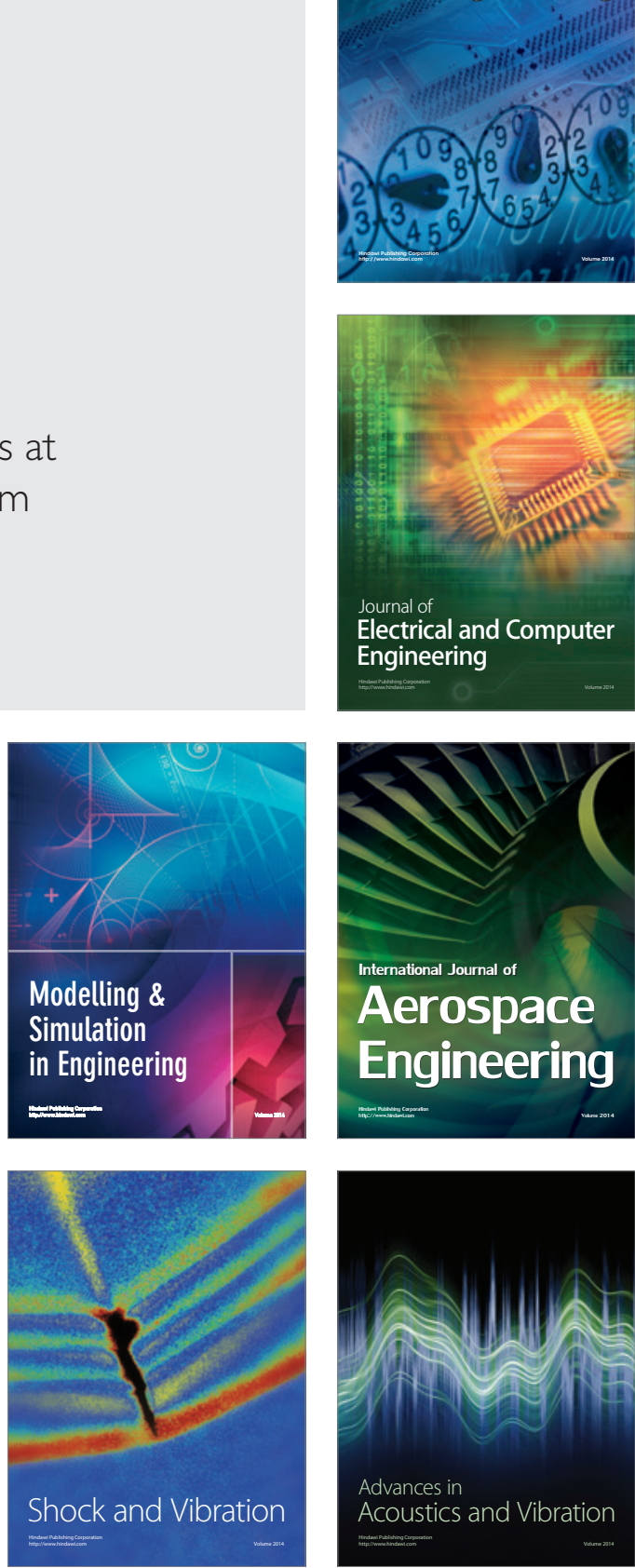